\title{
The role of liver biopsy in the management of patients with liver disease
}

\author{
Florence Wong MD FRACP FRCP(C)
}

\begin{abstract}
F Wong. The role of liver biopsy in the management of patients with liver disease. Can J Gastroenterol 2003;17(11):651-654.

The role of liver biopsy in the diagnosis and management of liver disease is a controversial issue even among hepatologists. Although most causes of elevated liver enzymes can be determined, or at least suspected, on the basis of a careful history and laboratory tests, histological assessment remains the gold standard for most liver diseases. Histological evaluation can either confirm or refute clinical diagnoses and can provide information about the severity and stage of disease. Occasionally, the liver biopsy also provides an additional diagnosis. The spectrum of nonalcoholic fatty liver disease accounts for a substantial proportion of cases of chronically elevated liver enzymes and can be reliably diagnosed only by liver biopsy. Prognostic information can be obtained in patients with this disorder, as well as in those with alcoholic liver disease and viral hepatitis, and liver biopsy can be used as a guide to their management.
\end{abstract}

Key Words: Alcoholic liver disease; Liver biopsy; Nonalcoholic steatohepatitis; Viral hepatitis

\section{Le rôle de la biopsie du foie dans le traitement des hépatopathies}

Le rôle de la biopsie du foie dans le diagnostic et le traitement des hépatopathies ne fait pas l'unanimité même parmi les hépatologues. Même si en général une anamnèse minutieuse et les examens de laboratoire permettent de trouver la cause de l'augmentation des enzymes hépatiques ou, tout au moins, d'en soupçonner l'origine, l'étude histologique constitue l'examen de référence pour la plupart des maladies du foie. Elle peut confirmer ou infirmer le diagnostic clinique et donner une indication du degré de gravité et d'évolution de la maladie. La biopsie du foie peut même parfois déboucher sur un diagnostic supplémentaire. Les stéatoses hépatiques non alcooliques sont à l'origine d'un nombre important de cas d'augmentation chronique des enzymes hépatiques, et seule la biopsie du foie permet de poser un diagnostic fiable. De plus, l'examen peut fournir des renseignements sur le pronostic de la maladie chez les patients atteints et chez ceux qui présentent une hépatopathie alcoolique ou une hépatite virale, et il peut même aider à orienter le traitement.

\begin{abstract}
A though there are many causes of liver disease (Table 1), recent advances in diagnostic techniques have led many physicians to question the need for liver biopsy (1-5). For example, alcoholic liver disease can often be diagnosed with a reliable history from the patient and family members, as well as clinical and biochemical evidence of chronic alcohol consumption. Viral and autoimmune hepatitis can be diagnosed serologically, while metabolic diseases can often be identified using genetic testing (Table 2). On the other hand, nonalcoholic steatohepatitis, a common cause of chronically abnormal liver enzymes, cannot be accurately diagnosed either clinically or radiologically (6). Therefore, many clinicians are now reconsidering the need for liver biopsy in patients with chronic liver enzyme abnormalities, and there is considerable disagreement among hepatologists on this issue.
\end{abstract}

\section{INDICATIONS FOR LIVER BIOPSY}

Liver biopsies are performed for diagnostic and prognostic reasons. Histopathological examination is the best method for making the diagnosis when noninvasive tests are inconclusive. In cases in which the diagnosis has already been established by other means, it may reveal additional diagnoses as well as information on disease severity. For example, although laboratory and imaging tests may suggest the presence of cirrhosis, liver biopsy remains the definitive procedure for this purpose. Moreover, it can help stage the disease and estimate its prognosis. Serial biopsies can document the progression of chronic conditions such as hepatitis $\mathrm{C}(\mathrm{HCV})$.

\section{CONTROVERSIES REGARDING LIVER BIOPSY}

If liver biopsies provide useful information for the management of patients with liver disease, why is there so much debate in the medical community about performing them? The explanation is that the procedure is associated with inconvenience, pain, and a risk of significant bleeding, albeit small (7). Therefore, experts disagree as to whether histologic assessment should be part of the standard management in patients with liver disease.

Sherwood and colleagues (5) retrospectively assessed the outcome of nearly 1000 patients with abnormal liver enzymes in the primary care setting. They found that only $57 \%$ of patients (531 of 933) were referred for specialized care. Of the remaining 342 patients who had follow-up visits, 157 had persistently abnormal liver enzymes, and were invited to return for further assessment. Liver biopsies were eventually performed in $101(64 \%)$ patients from this cohort, and yielded a definitive diagnosis in 81 patients despite normal serological tests. The authors concluded that a substantial proportion of patients with treatable and sometimes communicable chronic liver dis- 
TABLE 1

Causes of abnormal liver enzymes

Alcohol

Nonalcoholic steatohepatitis: Diabetes, hyperlipidemia, obesity

Viral: Hepatitis B, hepatitis C, other viruses

Autoimmune: Autoimmune hepatitis

Cholestasis: Primary biliary cirrhosis, primary sclerosing cholangitis, drugs Hereditary: Wilson's disease, hemochromatosis, $\alpha$-1-antitrypsin deficiency

\section{TABLE 2}

\section{Diagnosis of abnormal liver enzymes}

\section{Alcohol: History}

Nonalcoholic steatohepatitis: Physical exam, biochemistry

Viral: Serology, hepatitis B viral DNA, hepatitis C viral RNA

Autoimmune: Serology, immunoglobulins

Cholestasis: Serology, history

Hereditary: Biochemistry, genetic testing

ease would not have been diagnosed had they not undergone liver biopsy, and that the procedure remains a useful diagnostic tool.

In another retrospective study of 365 patients at university hepatology clinics, Spycher and colleagues (2) found that liver biopsy yielded an additional diagnosis in at least $10 \%$ of patients, and led to a change in diagnosis in $6.8 \%$. Overall, liver biopsy led to a change in the management of $12.1 \%$ of subjects. The authors therefore advised that, notwithstanding the presence of advanced virological, immunological and molecular genetic testing, there is an important role for liver biopsy.

In a prospective study involving 36 patients, Sorbi and colleagues (1) confirmed that liver biopsy changed the diagnosis in $14 \%$ of cases, and affected the frequency of liver test monitoring in 36\%. Treatment recommendations were altered in 12 of 36 cases, 10 of whom were offered investigational therapies. The authors, however, cautioned that the risks and benefits of a liver biopsy should be carefully weighed, especially in settings in which neither proven treatments nor investigational therapies are available.

It would seem obvious that, for patients with persistently abnormal liver enzymes of unknown etiology, liver biopsy would be regarded as a necessary diagnostic tool $(8,9)$. Indeed, Daniel and colleagues (3) reported that 73 of 81 patients with chronic liver disease of unknown etiology had abnormal liver biopsies, the most prevalent diagnosis being either steatosis or steatohepatitis. Because there is a poor correlation between the histological findings and the presence of obesity, hyperlipidemia or diabetes mellitus, liver biopsy remains the gold standard. Despite these findings, Kirsch (4) argued that the risks of liver biopsy far outweigh its benefits, especially since there is no definitive treatment for steatosis/steatohepatitis, and because histological diagnosis does not have a significant clinical impact for these patients.

Thus, it appears that the role of liver biopsy in the management of patients with liver disease remains controversial. The following is a summary of the published literature.

\footnotetext{
Alcoholic liver disease

There is a prevailing belief that alcoholic liver disease can be diagnosed with an acceptable degree of accuracy based on clinical findings together with biochemical tests (10). However,
}

solid evidence to support this statement is lacking. In one study, only $39 \%$ of physicians caring for patients with heavy alcohol intake used liver biopsy to make the diagnosis of alcoholic liver disease (10). In another prospective study, 347 men who chronically consumed more than $50 \mathrm{~g}$ of alcohol underwent liver biopsies irrespective of clinical or biochemical findings (11). Using specific clinical signs, including facial telangiectasia, vascular spiders, white nails, dilated abdominal wall veins, fatness and peripheral edema, the authors were able to accurately diagnose alcoholic cirrhosis in $90 \%$ of cases. They concluded that liver biopsy was probably unnecessary in the diagnosis of alcoholic cirrhosis.

All patients with alcoholic liver disease should undergo tests to exclude chronic HCV, because the two conditions frequently coexist. If abnormalities in liver biochemistry persist despite abstinence, or if the diagnosis of alcoholic liver disease is in doubt, a liver biopsy should be performed (12). Some studies suggest that, without histological confirmation, the diagnosis of alcoholic hepatitis is inaccurate in $10 \%$ to $20 \%$ of patients (10).

Serum biochemistry and the currently available imaging modalities have severe limitations in determining the relative contributions of fatty liver, alcoholic hepatitis and cirrhosis to the patient's disease. Histological examination is, therefore, of value in determining the prognosis for these patients. The characteristic features of alcoholic hepatitis include polymorphonuclear infiltrates, centrilobular hepatocyte swelling and degeneration, macrovesicular and microvesicular steatosis, Mallory bodies, and pericentral-perisinusoidal fibrosis (Figure 1). In $50 \%$ to $93 \%$ of cases, alcoholic hepatitis is superimposed on fully developed cirrhosis (13) and is associated with a significantly worse prognosis.

\section{Hepatitis C}

$\mathrm{HCV}$ infection is usually identified by the presence of HCV antibody or HCV RNA. The role of liver biopsy is to establish disease activity and the extent of fibrosis (14), which can significantly affect the outcome. Furthermore, data from studies involving serial biopsies have provided convincing evidence that the grade of fibrosis and the extent of inflammatory changes in the initial biopsy can predict the likelihood of eventual progression to cirrhosis (15). Therefore, a pre-treatment liver biopsy has been recommended to guide management $(16,17)$, especially since antiviral treatment is not necessarily benign and a successful outcome is not guaranteed.

With improvements in the outcome of treatment of $\mathrm{HCV}$, however, many experts now question the need for liver biopsy. In the Consensus Conference of the National Institutes of Health held in 2002, it was concluded that liver biopsy, although not mandatory, should still be performed in patients with HCV infection (18). The rationale of this decision is that patients with moderate to severe hepatitis on liver biopsy are likely to develop cirrhosis and therefore warrant immediate treatment, while treatment can be postponed for milder cases until more effective and tolerable options become available.

Pretreatment biopsy can help determine the prognosis after treatment. Although noninvasive laboratory markers can provide a crude estimate of the severity of inflammation and the extent of fibrosis, they are far less accurate than liver biopsy. In a systematic review of the literature, Gebo et al (19) reported that advanced fibrosis or cirrhosis on initial biopsy is associated with a modestly decreased likelihood of a sustained virolog- 
ical response to treatment. Biochemical and serological tests were best at identifying patients with no or minimal fibrosis, or those with advanced fibrosis/cirrhosis, but who were poor at grading intermediate levels of fibrosis. On the other hand, liver biopsy is useful at predicting the efficacy of treatment. This is particularly true for patients with coexisting steatosis or alcohol abuse, as both conditions have been shown to hasten the development of fibrosis $(20,21)$.

\section{Hepatitis B}

The literature about the role of liver biopsy in the management of patients with hepatitis $B(\mathrm{HBV})$ infection is much less extensive. This may be related to several aspects of the disease itself and of the available treatment options. Firstly, HBV is not cytotoxic; rather, it is the host's immune response to the virus that injures the liver. Therefore, the mere presence of an infection does not warrant a liver biopsy, which is most likely to be normal. Secondly, compared with HCV, the treatment for HBV is much more easily tolerated and widely applicable across the spectrum of infection, especially if nucleoside analogues like lamivudine or adefovir are used. Therefore, liver biopsy is not required to predict treatment outcome.

In the 2002 Consensus Conference of the European Association for the Study of Liver Disease (22), it was suggested that histological assessment of the extent of necroinflammation and the stage of fibrosis by an expert pathologist is an integral part of the management of patients with HBV infection. Liver biopsy could also identify other liver diseases. Serial biopsies have demonstrated significant histological improvement in $56 \%$ of patients who receive long-term lamivudine (23).

\section{Nonalcoholic fatty liver disease}

Nonalcoholic fatty liver disease (NAFLD) is a spectrum of disorders ranging from simple fatty liver to steatonecrosis and nonalcoholic steatohepatitis. It is associated with obesity, type II diabetes mellitus, hyperlipidemia, jejunoileal bypass and certain medications, but NAFLD can occur without identifiable risk factors (24). Patients typically present with unexplained chronic elevation of liver enzymes. Without treatment, a small number of patients with NAFLD develop cirrhosis $(6,25)$. This process is accelerated by the presence of $\mathrm{HCV}$ and iron overload $(20,26,27)$.

There are no direct correlations among the histological findings, liver enzyme abnormalities, radiological findings and the presence of obesity, hyperlipidemia or diabetes mellitus (3). Necroinflammatory changes on biopsy, however, may indicate an aggressive course with progression to liver cirrhosis (6). Therefore, many hepatologists advocate liver biopsy for all patients with abnormal liver enzymes who are suspected of having NAFLD.

Day (28) proposed the following indications for liver biopsy in patients with suspected NAFLD:

- alanine aminotransferase levels more than twice the upper limit of normal

- aspartate aminotransferase greater than alanine aminotransferase

- risk factors, including 'moderate' central obesity, noninsulin dependent diabetes mellitus, hypertension and hypertriglyceridemia

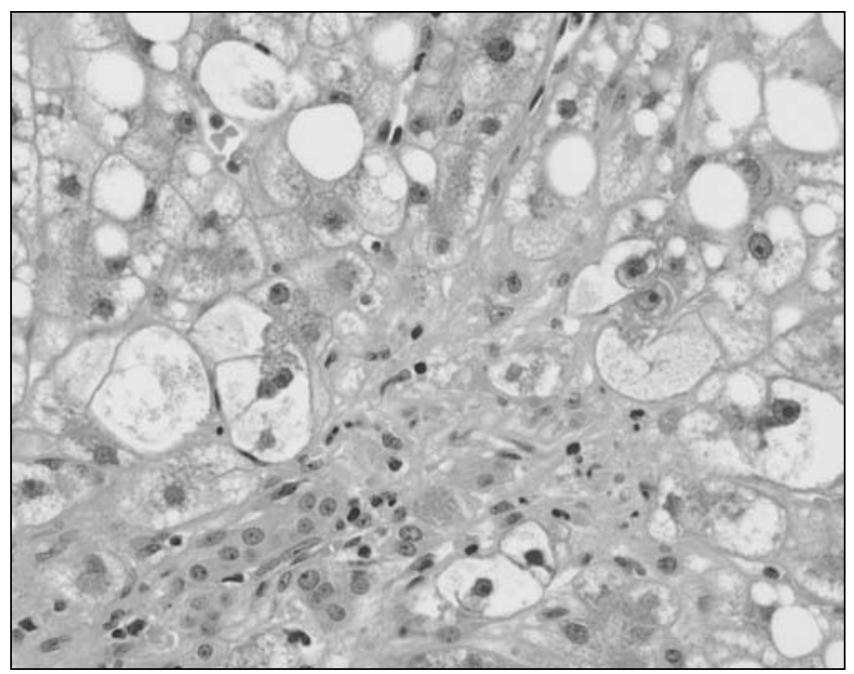

Figure 1) Photomicrograph of alcoholic steatohepatitis with inflammatory cells (including neutrophils), Mallory bodies and necrosis

On the other hand, McNair (29) argued that, since the only proven treatment for NAFLD is weight loss, liver biopsy was pointless. He stated that it is difficult to justify liver biopsy simply to provide better prognostic information. Indeed, it is not clear that patients with simple steatosis and mild fibrosis will not, with time, develop more severe liver disease. Likewise, Kirsch (4) did not feel that liver biopsy in patients with persistently abnormal liver enzymes should undergo a liver biopsy simply to make the diagnosis of NAFLD, since there is no defined therapy and knowing the histology is unlikely to have any clinical impact.

Matteoni and colleagues (6), in their 18-year study of patients with NAFLD, seem to have provided the answer. They found that patients with an isolated finding of steatosis had a benign course, while those with active inflammation, Mallory bodies, necrosis and fibrosis tend to develop cirrhosis. Therefore, liver biopsy not only provides important prognostic information but also remains crucial in the development of therapeutic protocols for NAFLD (30).

\section{CONCLUSION}

From the foregoing discussion, it can be seen that the role of liver biopsy in the management of patients with liver disease remains a contentious issue. Therefore, each case should be assessed on its own merits. For many patients, liver biopsy continues to provide important information about the cause and severity of the liver disease, and must be regarded as a crucial part of the patient's management. Emerging diagnostic tools, such as fibrosis markers, might make it possible to obtain this information noninvasively in the future. In the meantime, liver biopsy is required in selected patients with liver disease.

\section{REFERENCES}

1. Sorbi D, McGill DB, Thistle JL, Therneau TM, Henry J,

Lindor KD. An assessment of the role of liver biopsies in asymptomatic patients with chronic liver test abnormalities. Am J Gastro 2000;95:3206-10.

2. Spycher C, Zimmermann A, Reichen J. The diagnostic value of liver biopsy. BMC Gastroenterol 2001;1:12.

3. Daniel S, Ben-Menachem T, Vasudevan G, Ma CK, Blumenkehl M. Prospective evaluation of unexplained chronic liver transaminase abnormalities in asymptomatic and symptomatic patients. Am J Gastroenterol 1999;94:3010-4. 
4. Kirsch M. Liver biopsy without clear indication or informed consent. Am J Gastroenterol 2000;95:1588-9. (Lett)

5. Sherwood P, Lyburn I, Brown S, Ryder S. How are abnormal results for liver function tests dealt within primary care? Audit of yield and impact. BMJ 2001;322:276-8.

6. Matteoni CA, Younossi ZM, Gramlich T, Boparai N, Liu YC, McCullough AJ. Nonalcoholic fatty liver disease: A spectrum of clinical and pathological severity. Gastroenterology 1999;116:1413-9.

7. Piccinino F, Sagnelli E, Pasquale G, Giusti G. Complications following percutaneous liver biopsy: A multicentre retrospective study on 68,276 biopsies. J Hepatol 1986;2:165-73.

8. Diehl AM, Goodman Z, Ishak KG. Alcohol-like disease in nonalcoholics. A clinical and histologic comparison with alcoholinduced liver injury. Gastroenterology 1988;95:1056-62.

9. Van Ness MM, Diehl AM. Is liver biopsy useful in the evaluation of patients with chronically elevated liver enzymes? Ann Intern Med 1989;111:473-8.

10. Gluud A, Afroudakis A, Caballeria J, et al. Diagnosis and treatment of alcoholic liver disease in Europe. Gastroenterol Int 1993;6:221-30.

11. Hamberg KJ, Carstensen B, Sorensen TIA, Eghoje K. Accuracy of clinical diagnosis of cirrhosis among alcohol-abusing men. J Clin Epidemiol 1996;49:1295-301.

12. Bird GL. Investigation of alcoholic liver disease. Baillieres Clin Gastroenterol 1993;7:663-82.

13. Menon KVN, Gores GJ, Shah VH. Pathogenesis, diagnosis, and treatment of alcoholic liver disease. Mayo Clin Proc 2001;76:1021-9.

14. Perrillo RP. The role of liver biopsy in hepatitis C. Hepatology 1997;26(Suppl 1):57S-61S.

15. Poynard T, Bedossa P, Opolon P. Natural history of liver fibrosis progression in patients with chronic hepatitis C. The OBSVIRC, METAVIR, CLINIVIR, and DOSVIRC groups. Lancet 1997;349:825-32.

16. Sherman M. Management of viral hepatitis: Clinical and public health perspectives - a consensus statement. CASL Hepatitis Consensus Group. Canadian Association for Study of the Liver. Can J Gastroenterol 1997;11:407-16.

17. Saadeh S, Cammell G, Carey WD, Younossi Z, Barnes D, Easley K.
The role of liver biopsy in chronic hepatitis C. Hepatology 2001;33:196-200.

18. Dienstag JL. The role of liver biopsy in chronic hepatitis C. Hepatology 2002;36(Suppl 1):S152-60

19. Gebo KA, Herlong HF, Torbenson MS, et al. for the Johns Hopkins University Evidence Based Practice Center Team. Role of liver biopsy in management of chronic hepatitis C: A systematic review. Hepatology 2002;36:S161-72.

20. Castera L, Hezode C, Roudot-Thoraval F, et al. Worsening of steatosis is an independent factor of fibrosis progression in untreated patients with chronic hepatitis $\mathrm{C}$ and paired liver biopsies. Gut 2003;52:288-92.

21. Hezode C, Lonjon I, Roudot-Thoraval F, Pawlotsky JM, Zafrani ES, Dhumeaux D. Impact of moderate alcohol consumption on histological activity and fibrosis in patients with chronic hepatitis C, and specific influence of steatosis: A prospective study. Aliment Pharmacol Ther 2003;17:1031-7.

22. The EASL Jury. EASL International consensus conference on hepatitis B. J Hepatology 2003;38:533-40.

23. Dienstag JL, Goldin RD, Heathcote EJ, et al. Histological outcome during long-term lamivudine therapy. Gastroenterology 2003;124:105-17.

24. Schaffner F, Thaler H. Nonalcoholic fatty liver disease. Prog Liver Dis 1986;8:283-98.

25. Teli MR, James OFW, Burt AD, Bennett MK, Day CP. The natural history of nonalcoholic fatty liver: A follow-up study. Hepatology 1995;22:1714-9.

26. Bacon BR, Farahvash MJ, Janney CG, Neuschwander-Tetri BA. Non-alcoholic steatohepatitis: An expanded clinical entity. Gastroenterology 1994;107:1103-9.

27. George DK, Goldwurm S, MacDonald GA, et al. Increased hepatic iron concentration in nonalcoholic steatohepatitis is associated with increased fibrosis. Gastroenterology 1998;114:311-8.

28. Day CP. Non-alcoholic steatohepatitis (NASH): Where are we now and where are we going? Gut 2002;50:585-8.

29. McNair A. Non-alcoholic steatohepatitis (NASH): Why biopsy? Gut 2002;51:898. (Lett)

30. Angulo P. Current best treatment for non-alcoholic fatty liver disease. Expert Opin Pharmacother 2003;4:611-23. 


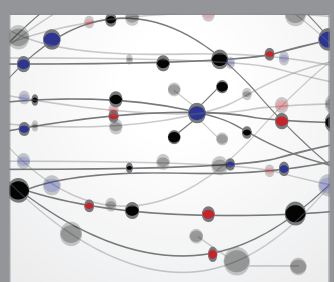

The Scientific World Journal
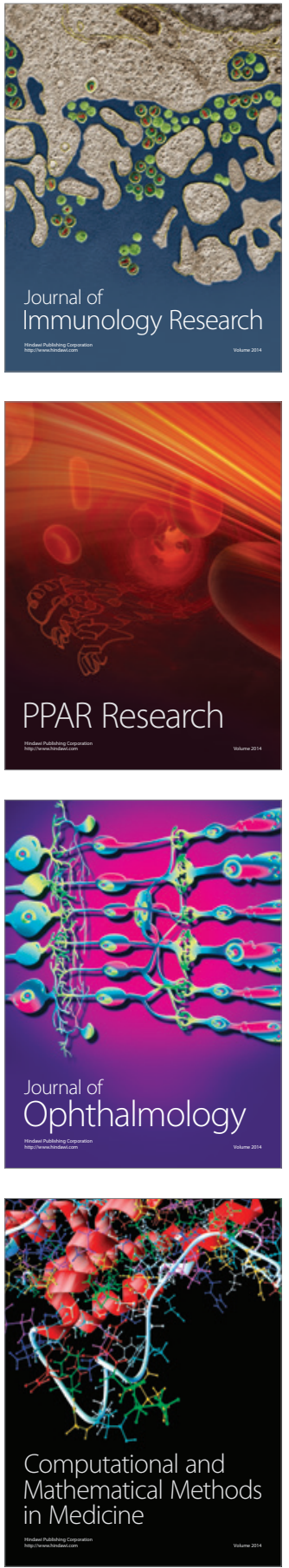

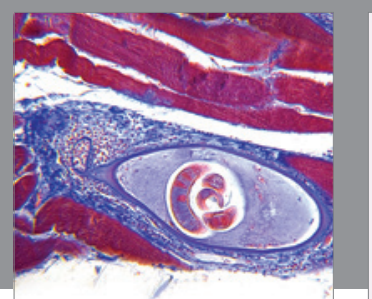

Gastroenterology Research and Practice

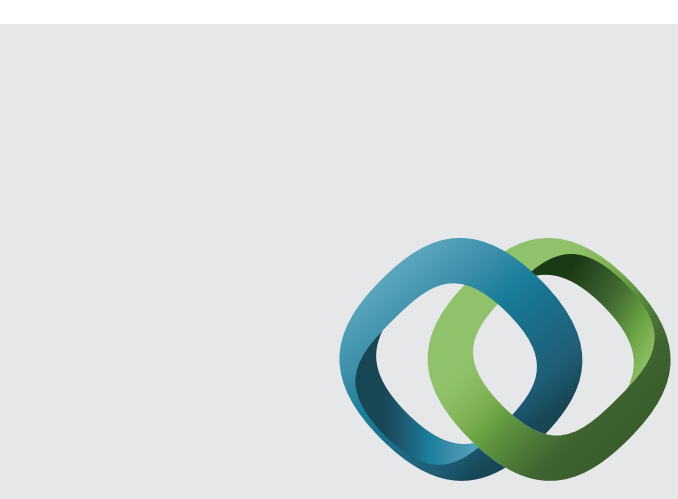

\section{Hindawi}

Submit your manuscripts at

http://www.hindawi.com
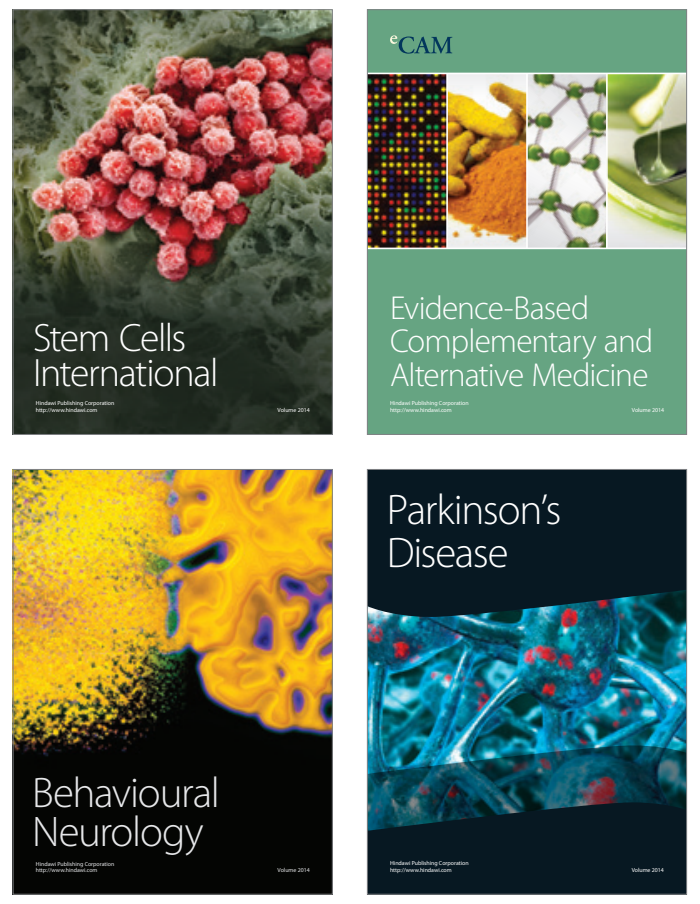
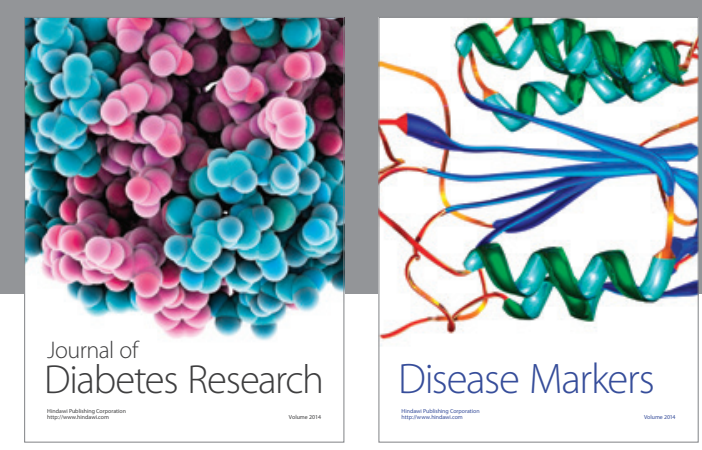

Disease Markers
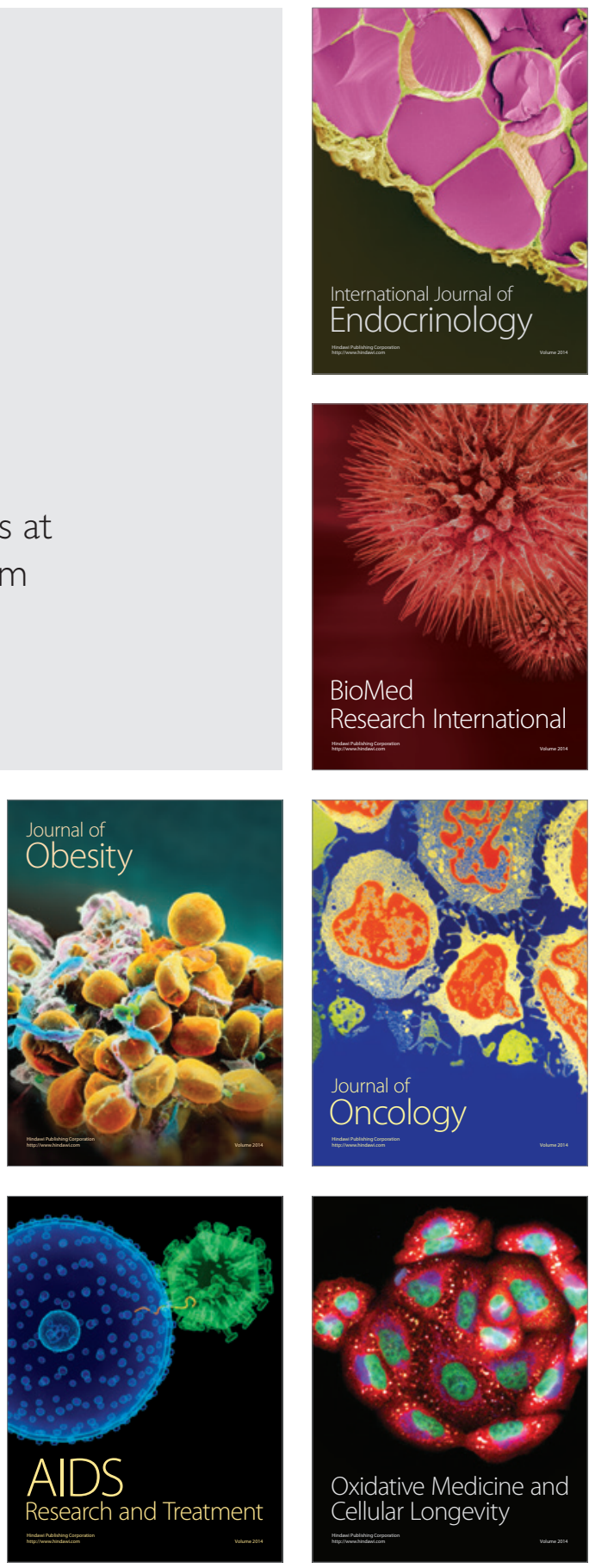